\title{
Interlocuções entre cultura física, discursos de saúde e relações de poder-saber na institucionalização do corpo saudável
}

\author{
Interlocutions between physical culture, health discourses and power- \\ knowledge relationships in the institutionalization of the healthy body \\ Interlocuciones entre cultura física, discursos de salud y relaciones de \\ poder-conocimiento en la institucionalización del cuerpo sano
}

\author{
Bel. João Paulo Marques ${ }^{1}$ \\ Dr. Pedro Navarro ${ }^{2}$ \\ Dra. Larissa Lara $^{3}$
}

\begin{abstract}
Resumo
Esse artigo objetiva analisar o envolvimento discursivo do corpo saudável com manifestações estruturais do poder disciplinar de instituições médicas de saúde. As análises propostas, orientadas por teorias foucaultianas e pelos estudos culturais físicos, atentam para questões concernentes à subjetivação, à institucionalização e à codificação discursiva dos corpos. Tecemos apontamentos acerca das transformações da concepção de saúde do corpo nas sociedades ocidentais, de como operam a produção de uma subjetividade do corpo saudável e de como tal subjetividade se articula a projetos neoliberais de individualização da responsabilidade pela saúde e de medicalização dos fenômenos sociais. Ainda, levantamos algumas inquietações a respeito das relações de podersaber que instituem essa subjetividade como produto e capital na rede de relações da indústria da saúde.
\end{abstract}

Palavras-chave: corpo saudável; cultura física; institucionalização corporal; poder-saber.

\section{Resumen}

Este artículo tiene como objetivo analizar la participación discursiva del cuerpo sano con manifestaciones estructurales del poder disciplinario de las instituciones de salud médica. Los análisis propuestos, guiados por teorías foucaultianas y estudios culturales físicos, prestan atención a temas relacionados con la subjetividad, la institucionalización y la codificación discursiva de los cuerpos. Tomamos notas sobre las transformaciones del concepto de salud corporal en las sociedades occidentales, cómo opera la producción de una subjetividad del cuerpo sano y cómo dicha subjetividad se articula a proyectos neoliberales de individualización de la responsabilidad de la salud y la medicalización de los fenómenos sociales. Aún así, planteamos algunas preocupaciones sobre las relaciones de poder-conocimiento que instituyen esta subjetividad como producto y capital en la red de relaciones de la industria de la salud.

Palabras claves: cuerpo saludable; cultura física; institucionalización corporal; puede-saber

Abstract

1 Bacharel em Educação Física; Universidade Estadual de Maringá-UEM; Maringá; Paraná; Brasil. a.marques.jp@gmail.com

${ }^{2}$ Doutor em Linguística e Língua Portuguesa; Universidade Estadual de Maringá-UEM; Maringá; Paraná; Brasil.navarro.pl@gmail.com

3 Doutora em Educação; Universidade Estadual de Maringá-UEM; Maringá; Paraná; Brasil. laramlara@hotmail.com 
This article aims to analyze the discursive involvement of the healthy body with structural manifestations of the disciplinary power of medical health institutions. The proposed discussions, guided by foucaultian theories and physical cultural studies, focus on issues concerning the subjectivation, institutionalization and discursive codification of bodies. We make notes about the transformations of the concept of body health in Western societies, of how the production of a subjectivity of the healthy body operates and of how such subjectivity is linked to neoliberal projects of individualization of responsibility for health and the medicalization of social phenomena. Still, we raise some concerns about the power-knowledge relationships that establish this subjectivity as a product and capital in the health industry's network of relationships.

Keywords: healthy body; physical culture; power-know; speech analysis.

\section{Introdução}

Esse artigo, de caráter bibliográfico exploratório e explicativo, é resultante de um amplo estudo ${ }^{4}$ que investiga e problematiza questões culturais físicas no tocante à institucionalização do corpo saudável e às relações de poder-saber afetas a instituições médicas de saúde. Desdobra-se a partir de problemáticas decorrentes do cotidiano de formação na universidade, questionando, a partir de experiências acadêmico-formativas, discursos postos em funcionamento por saberes que fundamentam tanto a formação quanto as práticas e as intervenções na área de educação física no contexto da saúde. Baseando-se nas discussões resultantes dessa pesquisa, propomos, nesse artigo, um exercício reflexivo que objetiva analisar o envolvimento discursivo do corpo saudável com manifestações estruturais do poder disciplinar de instituições médicas de saúde, com base em teorias foucaultianas e no campo investigativo conhecido como Physical Cultural Studies-PCS (LARA; RICH, 2017; LARA; LOPES; SOUZA, 2019).

A inclinação às questões da cultura física ${ }^{5}$ decorre do contato com o PCS e do interesse em manifestações e fenômenos que constituem o corpo e que o materializam como objeto de estudos na área da educação física. Desse movimento, emergem leituras, reflexões e análises que flertam com uma abordagem humanista do movimento corporal, atentando-se à pluralidade, à dinamicidade e à complexidade das relações estabelecidas entre corpo e cultura,

\footnotetext{
${ }^{4} \mathrm{O}$ estudo faz menção, especificamente, a pesquisas realizadas durante os anos de 2018 e 2019, vinculadas ao Departamento de Educação Física da Universidade Estadual de Maringá (DEF/UEM) e desenvolvidas em diálogo com o Grupo de Pesquisa Corpo, Cultura e Ludicidade (GPCCL/UEM/CNPq) e com o Grupo de Estudos Foucaultianos (GEF/UEM/CNPq). As pesquisas em questão se materializam no estudo intitulado Corpos subjetivados e institucionalizados: um estudo da cultura física na obra Routledge Handbook of Physical Cultural Studies (MARQUES; MIRANDA; LARA, 2019).

${ }^{5}$ Cultura física, bem como corpo e relações de poder-saber, são noções fundamentais para o campo Physical Cultural Studies. A cultura física diz respeito às diversas formas e possibilidades de manifestação do corpo em suas práticas, gestos, movimentos, entre outros. Essas formas de manifestação compreendem o corpo ativo, ou (in)ativo, que refere às formas de perceber, conhecer, aprender, comportar e interagir com a realidade, a qual, por sua vez, se estrutura a partir de tais relações.
} 
constituindo um esforço acadêmico à busca por uma perspectiva holística do sujeito. Algumas dessas análises focalizam os processos de subjetivação e de institucionalização dos corpos (MARQUES; MIRANDA; LARA, 2019), dando vazão a inquietações a respeito de como discursos postos em funcionamento na ordem da saúde se exercem sobre os corpos dos sujeitos em sociedade.

É desse movimento que irrompe a pesquisa que se deflagra nesse artigo, a qual se volta à investigação de conjunturas que possibilitaram às sociedades ocidentais falarem em uma saúde do corpo, ou ainda, em um corpo saudável (DANTAS, 2007; SANTOS, et al. 2019). Nessa investigação, atentamo-nos a relações de poder-saber estabelecidas entre medicina e sociedade a respeito da saúde e do corpo (MARQUES, 2019a). Por relações de poder-saber, compreendemos o modo como os discursos produzidos em uma dada sociedade sofrem uma série de coerções que configuram aquilo que Foucault (2006a) chama de "ordem discursiva". Soma-se a isso o fato de que o poder estrutura os saberes, configurando modos de ver e de falar do e sobre os sujeitos, seus corpos e seus discursos (FOUCAULT, 2006b). Assim, a partir das materialidades analisadas, que dão voz a pesquisadoras e pesquisadores orientadas/os às Ciências da Saúde, do Movimento, do Esporte, do Exercício, entre outras, evidenciamos a constituição de discursos em torno da saúde do corpo e como se apresentam em relação a práticas culturais físicas.

Por meio do exercício reflexivo materializado neste artigo, tecemos apontamentos relativos às transformações da concepção de saúde do corpo, relevantes para discutirmos sua produção discursiva e as conjunturas nas quais ele se insere nas sociedades ocidentais. Nesse sentido, os diálogos propostos buscam elucidar a produção e a institucionalização de uma subjetividade especificamente formulada em torno de concepções de saúde do corpo, às quais se articulam projetos neoliberais voltados à individualização da responsabilidade pela saúde e à medicalização dos fenômenos sociais. Contudo, cabe salientar que esse direcionamento analítico se atribui à perspectiva teórica mobilizada para o trabalho, que permitiu problematizar aspectos desses projetos em saberes constitutivos de noções de saúde afetos ao contexto no qual se desenvolve a pesquisa.

Assim, as discussões que compõem este trabalho são limitadas no que diz respeito a políticas que vão na contramão da individualização da responsabilidade pela saúde, empreendidas e aprimoradas em diversos níveis sociais e desdobrados em contextos como, por exemplo, o da saúde coletiva. Apesar dessa limitação, ressaltamos a importância de discussões nesse direcionamento analítico, uma vez que essas políticas se voltam, atualmente, a uma intervenção focada em aspectos constitutivos do sujeito humano (BATISTELLA, 2007; 
MINISTÉRIO DA SAÚDE, 2011). Além disso, esse esforço humanístico é atravessado por relações de poder-saber que desenham a ordem dos acontecimentos em sociedade, disputando espaço e força com projetos como os de políticas neoliberais de governo dos corpos. É nesse direcionamento que as discussões buscam levantar algumas inquietações a respeito das relações de poder-saber que instituem tal subjetividade do corpo saudável, incitando a reflexões que apontam para formas de envolvimento comercial da saúde em nossa sociedade.

Impulsiona a construção desse artigo uma sensibilidade que se identifica com o compromisso de teorizar o empírico, interpelar as relações estruturais de poder-saber de modo reflexivo e transdisciplinar, bem como denunciar formas de injustiças identificadas nas manifestações do corpo no contexto da cultura física (SILK; ANDREWS; THORPE, 2017). Nesse sentido, focalizamos o que alguns autores dos estudos culturais físicos chamam de cultura do corpo fisicamente ativo e capaz (HOWE, 2017; PARKER; WATSON, 2017), na qual se inscrevem os discursos e as instituições ${ }^{6}$ de saúde do corpo que atuam na subjetivação e na institucionalização dos sujeitos.

\subsection{Institucionalização e governamentalidade dos corpos}

Os estudos de Foucault acerca da relação entre poder e subjetividade centram-se em uma das noções mais caras às análises empreendidas nesse artigo, qual seja, a governamentalidade, que funciona como uma grade de leitura a partir da qual é possível analisar:

[...] a maneira como se conduz a conduta dos loucos, dos doentes, dos delinqüentes, das crianças -, como essa grade da governamentalidade também pode valer quando se trata de abordar fenômenos de outra escala, como por exemplo uma política econômica, como a gestão de todo o corpo social, etc. [...].(FOUCAULT, 2008, p. 258).

Referimo-nos ao exercício de um tipo de poder exercido sobre os indivíduos, que os posiciona como sujeitos nos discursos que se constituem a partir da fisicalidade, tal como discutida aqui. Assim, levamos em conta a existência de certa interatividade entre a subjetivação e a institucionalização corporal (Cf. MARQUES, 2019b; MARQUES; MIRANDA; LARA, 2019). A partir de nossa compreensão, a subjetivação corporal, mediada pela governamentalidade dos corpos, informa a perspectiva de in-corporação (embodiment) ${ }^{7}$

\footnotetext{
${ }^{6} \mathrm{O}$ termo "instituição" é entendido nesse artigo como "todo comportamento mais ou menos coercitivo, aprendido. Tudo que em uma sociedade funciona como sistema de coerção, sem ser um enunciado, ou seja, todo social não discursivo é a instituição" (FOUCAULT, 2012, p. 368).

${ }^{7}$ Assumimos in-corporação como tradução de embodiment, apesar de entendermos que essa tradução não tem a mesma potência simbólica que a palavra tem em sua língua original. O termo está relacionado a práticas, experiências e processos vividos em que o sujeito, nas relações consigo, com os outros e com o meio cultural,
} 
de uma equalização de normas prescritivas assumidas por tecnologias disciplinares na codificação de singularidades físicas. Tais tecnologias instituem no simbólico e/ou imaginário da memória coletiva valores, gostos, hábitos e comportamentos específicos, constituindo expectativas de comportamento orientadas a essas singularidades. Pelo investimento de aspectos distintivos e categóricos que hierarquizam e classificam os sujeitos, tais singularidades físicas permitem sua identificação e codificação em torno das normativas prescritivas, qualificando e distinguindo socialmente corpos e subjetividades.

A subjetivação dos corpos os torna produtos constantemente reformulados a partir de operações internas desencadeadas por forças externamente orientadas, as quais atuam significando suas relações e experiências e as representando em níveis afetivos, psíquicos, simbólicos, discursivos e materiais. Por meio dessas operações de força e de poder é que entendemos a institucionalização corporal, que diz respeito à modulação de comportamentos, hábitos, valores e da própria subjetividade em relação às normas prescritivas e às individualidades dos corpos. Esse fenômeno é por nós contextualizado sob a perspectiva de uma rede de poder tensional voltada à governamentalidade da vida, que enuncia, ao mesmo tempo, os pontos de aplicação das relações de poder-saber presentes nesses locais, as posições dos sujeitos envolvidos e os discursos produzidos (FOUCAULT, 2005; 2012; 2015).

Ao focalizar essa rede de forças buscamos denunciar formas de desigualdade e de injustiça operadas pelo exercício desse tipo de poder nas particularidades dos corpos, evidenciando, para tanto, estratégias discursivas identificadas nessas operações e que compõem as tecnologias disciplinares orientadas pela governamentalidade/por um poder governamental. É, portanto, a partir dessas formulações que entendemos a interatividade da subjetivação e da institucionalização corporal, analisadas como processos de operação de saberes enunciados em ordens distintas e que, no entanto, inscrevem epistemes ${ }^{8}$ específicas

constrói-se como agente transformador, ativo, que ressignifica, reinterpreta, expressa atitudes, afetos, potência de vida. Lara e Rich $(2019$, p. 1311) entendem que "a palavra embodiment tem sido frequentemente utilizada no campo da produção em arte, no contexto brasileiro, em sua expressão original na língua inglesa, dada a inexistência de um termo correlato capaz de dimensioná-lo", dificuldade que se estende, na nossa percepção, a outras áreas do conhecimento. As autoras argumentam que "[...] o sentido de embodiment sugere a percepção do sujeito em sua dimensão holística a partir de um corpo vivido, experimentado, in-corporado, encontrado em si mesmo e na relação com o outro, percebido como um composto unitário relacional entre matéria, desejo, consciência, emoções e subjetividade" (p.1311). Csordas (1994), por sua vez, descreve o embodiment como fundamento existencial da cultura e do eu, ou ainda como condição existencial da vida cultural, em que os valores culturais são inscritos no corpo. Nesse caminho, o embodiment não se reduz a representações do corpo, a sua objetificação, a suas dimensões física e biológica, mas se deflagra por diferentes caminhos que apontam para o corpo como experiência que congrega afetos, emoção, dor, ritual, hábitos, entre outros, momento em que a experiência humana vivida é refletida, superando a interpretação passiva do corpo e sua apreensão dicotômica.

8 Consideramos, aqui, o entendimento de Foucault (2012, p. 367) acerca da épistémè: "um dispositivo especificamente discursivo" que permite a escolha estratégica de enunciados passíveis de aceitação em determinado campo de cientificidade. A partir desses enunciados específicos, entre vários, é possível qualificar o 
nos corpos. Tais inscrições configuram-se nas relações afetivas dos sujeitos com as instituições sociais, dentre as quais buscamos focalizar as instituições médicas de saúde.

Nesse artigo, as instituições médicas de saúde remetem à forma como interagimos com conhecimentos e funções discursivas de ordem médica, assim como a seus efeitos em termos de subjetivação e de institucionalização dos corpos, relativamente à sua saúde. Assim, ao tratarmos do corpo e de suas relações discursivas e culturais físicas, reconhecemos a transcrição e/ou a incorporação de valores, costumes, regras, códigos, virtuosidades e estéticas específicas da ética atribuída a dada episteme (CLARA, 2011; FOUCAULT, 2012), mediadas por tais instituições. Trata-se, portanto, de formas estéticas configuradas por éticas próprias das contextualidades às quais se articulam tais instituições em sua historicidade e que, como entendemos, evidenciam-se pela discursividade dos corpos como formas de expressão da fisicalidade ${ }^{9}$.

\section{Proposta analítica e constituição do arquivo sob investigação}

As investigações da institucionalização do corpo saudável empreendidas na pesquisa a partir da qual elaboramos esse artigo se baseiam em saberes formativos afetos à área da Educação Física brasileira, bem como em problemáticas identificadas no campo investigativo dos estudos culturais físicos - forma como o PCS vem sendo referido no Brasil (LARA; LOPES; SOUZA, 2019). Desse modo, o material que subsidia as reflexões pertinentes ao envolvimento cultural físico do corpo refere-se a quinze capítulos da coletânea Routledge Handbook of Physical Cultural Studies, organizada por Silk, Andrews e Thorpe (2017). Tais capítulos se distribuem em duas partes que tratam desse envolvimento sob as temáticas da subjetivação e da institucionalização corporal.

A subjetivação corporal é diretamente problematizada em sete capítulos que tratam do corpo e da cultura física nas perspectivas de classe (Alan Bairner), raça (Bem Carrington), gênero (Clifton Evers e Jennifer Germon), sexualidade (Megan Chawansky e Satoko Itani), deficiência (David Howe), juventude (Louise McCuaig, Eimear Enright e Doune Macdonald) e longevidade (Cassandra Phoenix). Já a institucionalização corporal é discutida especificamente em oito capítulos referentes aos corpos obeso (Michael Gard), estético (Julia

científico e o não-científico, a veracidade e a falsidade de um discurso e, assim, aquilo que é aceitável e repreensível em uma dada contextualidade.

${ }^{9}$ Categoria fluida que diz respeito à pluralidade de possibilidades de experienciar e de expressar as relações estabelecidas entre corpo e realidade (GIARDINA; NEWMAN, 2011) ou, em outros termos, às experiências embodied. 
Coffey), digitalizado (Debora Lupton), religioso e espiritualizado (Andrew Parker e Nick J. Watson), medicalizado e cientificizado (Parissa Safai), erotizado e espetacularizado (Toby Miller), mediado e comodificado (David Rowe) e punido (Aaron Miller).

Além dos trabalhos mencionados, a pesquisa buscou aporte teórico-analítico nos estudos discursivos foucaultianos realizados no Brasil, pautando-se, para isso, nas obras Vigiar e Punir: nascimento da prisão (FOUCAULT, 2014), A Verdade e as Formas Jurídicas (FOUCAULT, 2005) e Microfísica do Poder (FOUCAULT, 2012). Além dessas obras, mobilizamos reflexões pertinentes ao discursivo do corpo diante da medicina, por meio de um capítulo do terceiro volume da obra História do Corpo (CORBIN; COURTINE; VIGARELLO, 2011) e da tese de Dantas (2007), que trata da produção biopolítica do corpo saudável.

\section{Produzindo um saber médico acerca da saúde do corpo}

As investigações envolvendo as possíveis relações entre corpo e instituições médicas de saúde ampararam-se no trabalho da médica francesa Anne-Marie Moulin (2011). Seus relatos exploram os acontecimentos relativos à autonomia da medicina, bem como do próprio corpo em relação a ela, ao tratar da medicalização das sociedades ocidentais. Por meio de tais relatos abordamos questões afetas ao reconhecimento do direito à doença pelo Estado providência do século XIX, questões que demonstram como esse reconhecimento daria vazão, no início do século $\mathrm{XX}$, aos direitos à saúde, à plena realização da pessoa e à assistência médica, caros à nossa sociedade até os dias atuais.

Em seus relatos, observamos relações estruturais envolvendo as esferas política, social e histórica que apontam para a construção de um cenário em que a doença é desqualificada em prol da emergência da saúde como um valor positivo, estruturando-se como um direito dos sujeitos. Nesse contexto, a saúde passa a ser reconhecida e valorizada como um direito individual, socialmente conquistado pelas vitórias da medicina ocidental sobre a doença ao longo dos anos. No entanto, a desqualificação da doença envolve o rompimento com o ritual que permite aos sujeitos identificarem esse estado, sendo esse ritual caracterizado pela vivência dos momentos de crise e morte, ou de convalescência e gratidão (MOULIN, 2011).

O rompimento com o ritual da doença, segundo Moulin, conduz a um progressivo distanciamento de tais momentos, privando os sujeitos das experiências associadas a eles e retirando esses momentos da memória coletiva. Essa configuração leva a autora a afirmar que os indivíduos da nossa sociedade não sabem mais estar doentes. Ademais, observamos que o 
cenário sob o qual a autora realiza tal afirmação aproxima-se do contexto político-social descrito por Foucault (2014) em relação à distribuição da disciplina para a administração espacial dos corpos. Essa observação conduz nossa atenção para uma transformação discursiva que reformula o status da saúde do corpo nas sociedades ocidentais.

A organização técnica e sistemática das formas de distribuição social da disciplina ${ }^{10}$ para a administração dos corpos é explicada por Foucault em sua obra: Vigiar e Punir. Especialmente por meio da noção de quadro, podemos observar como ocorre, ao longo da história, o movimento de esquadrinhamento ${ }^{11}$ das doenças e suas contribuições para o distanciamento do ritual da doença na memória coletiva. Tais contribuições são sinalizadas nos relatos, de modo aparente, com um deslocamento do sujeito acometido para um espaço físico específico, com a transferência da responsabilidade pela cura a um profissional e com a individualização e medicalização do processo saúde doença.

Tais fatores convergem aos intentos das operações da disciplina nos corpos da população, operada a partir do que Foucault (2014) chama de "quadros vivos": formas de organização das multidões (e de suas multiplicidades), e contribuem para o referido distanciamento, uma vez que o processo de recuperação de uma enfermidade tende a ser cada vez mais individualizado e administrado por profissionais especializados, tomando proporções progressivamente mais horizontais na relação médico-paciente, apesar das medidas de atuação e de conduta profissional, como relembra Moulin (2011).

Estabelecer um quadro/esquadrinhar a população permite distribuir, analisar, controlar e tornar inteligível a disciplina operada nos corpos, por exemplo, pelas instituições hospitalares (FOUCAULT, 2014; MOULIN, 2011). Entretanto, tal operação transcende o limiar dos corpos acometidos por doenças, estendendo-se aos demais corpos da população. Um exemplo dessa extensão materializa-se no plano das relações de trabalho, como teorizado por Amorim et al. (2017) ao tratarem de alguns efeitos da institucionalização de práticas corporais gerados por uma rotina de práticas engessadas e de hábitos controlados em relação

\footnotetext{
${ }^{10} \mathrm{O}$ conceito de disciplina foucaultiano diz respeito a uma "gigantesca série de instituições que vão enquadrar os indivíduos ao longo de sua existência (FOUCAULT, 2005, p. 86)", ou seja, a dispositivos exercidos sobre os corpos e operados em nível das periculosidades dos indivíduos, de seus desejos, medos, vontades, pensamentos e ações, daquilo que se encontram na iminência de fazer. Em relação à busca pela institucionalização do corpo saudável, esse conceito faz menção às formas metódicas para se alcançar os níveis e status de saúde pretendidos para as sociedades em sua historicidade.

${ }^{11} \mathrm{O}$ esquadrinhamento em Foucault refere-se à capacidade de gerir os corpos nos espaços sociais. No entanto, essa administração dos corpos não ocorre de modo externo a sua materialidade, ao contrário, materializa-se na instituição de forças externas que atuam na regulação das operações internas do corpo, constituindo relações de poder-saber que atuam sobre os aspectos mais ínfimos da vida dos indivíduos (FOUCAULT, 2012).
} 
aos gestos motores e aos hábitos de comportamento, moldados por instituições médicohospitalares em profissionais de saúde mental (AMORIM, et al., 2017).

Abordar o esquadrinhamento das doenças e dos corpos torna-se relevante para esse exercício reflexivo, na medida em que é desse cenário que emergem as condições e as justificativas legais para a promulgação de regras de comportamento, para a privação de prazeres e para as recomendações cotidianas aprisionadoras afetas à saúde (FOUCAULT, 2014). Tais condições associam-se ao investimento feito pelo Estado para a produção de um efeito de verdade (FOUCAULT, 2005) da saúde como uma concepção social positiva (MOULIN, 2011). Assim, esse investimento articula-se à atribuição do monopólio da medicalização social à medicina, responsabilizando-a pela gestão social dos corpos em relação a todos os grandes acontecimentos da socialização relativos à saúde pública. Com essa responsabilidade, os discursos instituídos pela medicina ocidental passam a focalizar a saúde do 'corpo social' e a valorização do direito individual à saúde (MOULIN, 2011).

Com a ação da medicina orientada à gestão dos corpos, "a saúde passou a ser a verdade e também a utopia do corpo, aposta da ordem social e de uma ordem internacional futura, mais equitativa e mais justa, no conjunto do mundo" (MOULIN, 2011, p. 18). Desse modo, as instituições médicas passaram a atuar na educação do corpo e na produção de sentidos que constituem um "modo médico de ver" (SAFAI, 2017). Essa visão medicalizada da realidade passa a agir sobre os sujeitos, interpelando seus corpos nas esferas públicas e privadas e fazendo emergir, juntamente com a noção de risco, um ideal coletivo de decência que visa combater um "novo pecado original".

Se o médico se tornou perito em todos os assuntos públicos e privados, é porque toda pessoa saudável é um doente que se ignora. [...] O conhecimento médico vai agora muito além dos sintomas englobando órgão e funções silenciosas. [...] Trazemos dentro de nós mesmos um novo pecado original, modificado pelo nosso meio ambiente natural e sociocultural e pelo nosso modo de vida. [...] Aí está situado o paradoxo de grande aventura do corpo no século XX. O exibicionismo da doença não é mais admissível, reduzido pelo ideal de decência. O corpo é lugar onde a pessoa deve esforçar-se para parecer que vai bem de saúde (MOULIN, 2011, p. 19-20).

O que ressaltamos frente ao pensamento elaborado até então é o investimento moral e pessoal da saúde do corpo, envolvendo-o com as demais esferas da realidade social e da vida humana, a exemplo das esferas jurídica, política e simbólica, entre outras. Essa ressalva converge com os apontamentos de Dantas (2007) e Prado (2007), os quais destacam a produção midiática de uma narrativa composta por uma multiplicidade de discursos acerca do corpo saudável e que se mostram, por vezes, contraditórios no que tange a sua atribuição 
valorativa. Destacamos que a contraditoriedade dos discursos orientados ao corpo saudável na atualidade lança luz ao seu caráter de dispositivo, uma vez que este constitui "um conjunto decididamente heterogêneo que engloba discursos, instituições, organizações arquitetônicas, decisões regulamentares, leis, medidas administrativas, enunciados científicos, proposições filosóficas, morais, filantrópicas" (FOUCAULT, 2012, p. 364).

Assim, diante das análises empreendidas na pesquisa, entendemos que o dispositivo do corpo saudável, como "estratégias de relações de força sustentando tipos de saber e sendo sustentadas por eles" (FOUCAULT, 2012, p. 367), configura-se nas relações de poder-saber estabelecidas entre as instituições médicas e o Estado. A presença desse dispositivo nas relações sociais se mostra nos relatos de Moulin e de Foucault acerca da propagação do saber médico, que ocorre a partir de mecanismos biopolíticos que suscitam transformações no modo de viver dos sujeitos. Identificar a função desse dispositivo nas discussões implica ressaltar que esse tipo de dispositivo, ao se instaurar no tecido sócio-histórico, produz sentidos de verdade que instituem modos específicos de se relacionar com o corpo. Tais especificidades, mediadas por saberes ordenados pelas instituições médicas, fazem funcionar o mecanismo social da saúde, que permite o exercício do poder disciplinar.

\section{Envolvendo-se discursivamente com o corpo saudável}

O contraste dos discursos de saúde, como observado por Dantas, aponta para novas demandas sociais que demonstram certa superação da lógica da sociedade disciplinar de que trata Foucault, na qual a saúde possuía caminhos metódicos para ser alcançada. Segundo o autor, tais discursos desvelam "formas extremas de sermos saudáveis" (DANTAS, 2007, p. 69). Essa afirmação concerne com a função social da medicina, que atua regulamentando práticas de saúde diversificadas e estendidas a toda a população, quando considerado que as transformações no ambiente natural fizeram com que todos os sujeitos fossem considerados doentes em potencial (MOULIN, 2011).

Desse envolvimento da medicina social na vida política decorre a produção de uma multiplicidade de discursos a respeito da saúde dos corpos (DANTAS, 2007), os quais operam diretamente na pessoalidade dos sujeitos, coagindo suas individualidades e instituindo formas de pensar e de agir que mediam a atribuição de valores às fisicalidades dos corpos (FOUCAULT, 2014). Devido a essa operação, a função social da medicina pode ser 
aproximada à do que entendemos como mecanismo disciplinar ${ }^{12}$, a partir das elaborações de Foucault (2014). Na perspectiva desse mecanismo, os enunciados discursivos sobre a saúde do corpo findam por atuar em dispositivos de controle e de vigilância dos corpos. Como analisa Foucault (2014), esse tipo de dispositivo instaura no tecido sócio-hitórico efeitos e sentidos de verdade que instituem novos modos de se relacionar com o corpo, de atribuir significados a seus movimentos e a suas experiências.

Ressaltamos, no entanto, que tais sentidos ocultam o caráter coercitivo e o próprio movimento de subjetivação que ocorrem com o funcionamento desse tipo de dispositivo, os quais enunciam sua operação na ordem da docilização e da normalização das multiplicidades e individualidades dos corpos. Ademais, articulamos essa ressalva às medidas adotadas pela medicina para a produção do valor social positivo da saúde, como relatado por Moulin (2011) ao denunciar o apagamento das condições pelas quais esse valor foi produzido. Nessa denúncia, Moulin atenta para a violação e para a exploração das populações vistas como minoritárias - aquelas em condições de vulnerabilidade política, social e econômica - e para o ocultamento dessa condição, gestada pelo interesse político nos benefícios obtidos pela medicina social, majoritariamente de caráter econômico e tecnológico.

A denúncia da autora desvela que tal apagamento associa-se à intenção de produzir uma narrativa que apontasse para a importância que possui a saúde para a população, narrativa essa que se apresenta por meio de discursos voltados à valorização do cuidado com o corpo (pessoal e social) e com a longevidade, por exemplo. Entretanto, tal narrativa articulase estrategicamente a discursos que, para além de defenderem a busca pela saúde e de ocultarem seu envolvimento com a invenção de uma verdade do tipo profética e prescritiva, atuam no exercício de um poder gestacional e governamental dos corpos (FOUCAULT, 2014; 2005). A partir das materialidades analisadas, observamos que a construção dessa narrativa é atribuída ao projeto biomédico que subsidia a medicalização dos fenômenos sociais, bem como dos corpos.

A medicalização dos fenômenos sociais implica em identificar as relações possíveis entre os sujeitos e os fenômenos sociais com a saúde para que, intervindo nessas relações, os discursos enunciados na ordem (bio)médica consolidem a reivindicação dessa organização pelo poder de autoridade pericial quanto a tudo o que diz respeito à saúde do corpo (MOULIN, 2011; SAFAI, 2017; CRAWFORD, 2006). Tal medicalização está intimamente

12 O mecanismo disciplinar descrito por Foucault (2014) é comporto por três dispositivos historicamente aprimorados para punir os corpos dos sujeitos para além de suas funções orgânicas, incidindo na iminência de seus pensamentos e ações. São eles: a) o olho do poder; b) as sanções normalizadoras e c) o exame. 
relacionada com o healthismo - fenômeno descrito por Crawford (2006) como uma 'formulação ideológica'13 extremista de atribuição individual da responsabilidade pelos cuidados em saúde pública e pessoal. Em diálogo com o autor, Safai (2017) aponta que o healthismo, no âmbito das políticas públicas, constitui uma estratégia de reorientação coletiva das abordagens em saúde.

Enquanto estratégia de intervenção comportamental, o healthismo eleva a etiologia pessoal da doença em detrimento da social e da estrutural e, com isso, centraliza as questões de saúde e de doença no sujeito, retirando das discussões a responsabilidade legal atribuída ao Estado pela saúde da população (CRAWFORD, 2006; SAFAI, 2017). O caminho pelo qual essa estratégia de individualização do cuidado com a saúde se institui no tecido social é apontado por Crawford (2006) como sendo o da própria linguagem. Segundo o autor, essa estratégia é atravessada pelo simbólico do sagrado e do mundano da cultura instrumentalracional, atravessamento que camufla significados inscritos na ordem da naturalidade e que, com isso, tomam formas em práticas de autorização e validação de ações sociais.

Um exemplo desse atravessamento alertado por Crawford é a narrativa de que um corpo não-saudável decorre da incapacidade do sujeito de resistir a formas e a hábitos de consumo culturalmente construídos, ou mesmo de aderir a hábitos considerados saudáveis, como a prática regular de atividade física e o controle alimentar (SAFAI, 2017). Segundo Safai (2017), essa concepção da saúde como responsabilidade individual é naturalizada na memória coletiva por meio de dogmas que reforçam a "ideologia da classe média"14. Tais dogmas manifestam-se por meio de sintagmas cristalizados, tais como: 'força de vontade', 'autodisciplina' e 'estilo de vida'. Além disso, esses dogmas são institucionalizados nas práticas de saúde devido a sua incorporação aos/pelos discursos enunciados por estratégias e por programas de políticas públicas orientadas pelo pensamento neoliberal.

A institucionalização ideológica da responsabilidade individual pela saúde no âmbito das relações políticas, sociais e estruturais favorece o que alguns autores chamam de culto ao corpo fisicamente ativo e capaz (HOWE, 2017; PARKER; WATSON, 2017). Tal culto

\footnotetext{
${ }^{13}$ Entendemos que "a ideologia é um conjunto lógico, sistemático e coerente de representações (ideias e valores) e de normas ou regras (de conduta) que indicam e prescrevem aos membros da sociedade o que devem pensar e como devem pensar, o que devem valorizar e como devem valorizar, o que devem sentir e como devem sentir, o que devem fazer e como devem fazer" (CHAUÍ, 2008, p. 108-109). O termo ideologia, presente nessa passagem, emerge no material de análise, a partir da orientação teórico-analítica de Crawford (2006), sendo mantido para não descaracterizar a questão levantada pelo autor. No entanto, ressaltamos que, no escopo desse trabalho, essa perspectiva não coaduna com a das relações de poder, conforme a perspectiva de Foucault.

${ }^{14}$ Tal ideologia faz menção a uma linguagem comum à classe média, como um marcador ou sinalizador das relações interpessoais, estabelecido a partir do desenvolvimento de sentidos e das expressões linguísticas mobilizadas na comunicação e no cotidiano das relações. Essa noção também é discutida no estudo de Crawford (2006).
} 
apresenta-se, no material analisado, em meio a discussões voltadas às experiências incorporadas (embodied) ${ }^{15}$ vivenciadas pelos sujeitos no contexto esportivo. Essas discussões abordam o corpo nas perspectivas da deficiência física e da espiritualidade, sob a sensibilidade dos estudos culturais físicos, aludindo a normas de julgamento e de qualificação dos padrões de movimento corporal e da estética das formas físicas. Além disso, tais discussões demonstram a dimensão estética como pano de fundo para atos voltados à normalização, à comodificação e à celebração da perfeição corporal.

Diante das discussões envolvendo o culto à atividade e à capacidade dos corpos, os autores destacam a valorização de aspectos como espontaneidade, consumismo, impulsividade, juventude, excitabilidade, beleza, força, individualidade e autossuficiência, articulados e/ou atravessados por ideais utilitaristas, racionalistas, capitalistas e de poder de livre mercado. De acordo com Parker e Watson (2017), o culto à normalidade mantido pela cultura dominante em nossa sociedade, que preza por princípios como individualidade, autossuficiência e nacionalismo, distribui-se, a partir desses valores, por meio de ritos sociais que atuam na despersonalização dos sujeitos. Nesse sentido, corroboramos as argumentações dos autores ao afirmarem que a 'tirania da normalidade' leva à alienação pessoal e social e "agarra a nossa cultura de tal modo que muitas vezes negamos sua existência, preferindo reprimir nossos próprios medos e inseguranças e assim manter o status quo" (PARKER; WATSON, 2017, p. 213, tradução nossa).

Desse modo, observamos que a busca constante pela melhora da saúde e da qualidade de vida, como rito social produzido pelas instituições médicas, caracteriza uma prática de negação inconsciente enunciada por uma saúde fictícia que sustenta diversas instituições em nossa sociedade, incluindo o esporte, como pontuam os próprios autores. É no direcionamento dessa observação que tecemos apontamentos quanto aos modos como práticas culturais físicas podem mobilizar valores e hábitos de comportamento como intrínsecos a um corpo saudável, uma vez que a saúde se tornou um produto na sociedade medicalizada.

\footnotetext{
15 Vieira (2013) argumenta que o "nosso crescimento, aprendizado e desenvolvimento como arteeducadores/pesquisadores incluem in-corporação (embodiment) de experiências transformadoras [...]" (p.179). Observa a existência de duas dinâmicas no processo de embodiment que avalia como fundamentais: "o nosso 'eu' que já trazemos construído a partir de nossas histórias de vida e o embodiment que se constrói no nosso diaa-dia de relações com o outro e o meio ambiente que nos cerca" (p. 179), embora a divisão seja meramente didática. A autora afirma que o conhecimento tem suas chances ampliadas de se tornar in-corporado (embodied) quando "nossas múltiplas maneiras de perceber" são acionadas por meio de conexões e mediações que apontem para diferentes caminhos, o que nos leva a "in-corporar (embody) significados no grau máximo" (p.180). Tais significados também se transformam, como nós. Nas suas palavras: "Acredito ainda que para que fatos, acontecimentos, experiências, e vivências fiquem embodied ou façam realmente parte do nosso ser, das nossas memórias e histórias de vida, é necessário que estejamos corporalmente engajados no momento que se vive" (VIEIRA, 2013, p.180). Cf. também experiências in-corporadas (embodied) em pesquisas desenvolvidas por Francombe-Webb e Silk (2016), Francombe-Webb, Rich e De Pian (2014).
} 


\section{O corpo saudável como mercadoria de identificação}

Ao longo das análises empreendidas na pesquisa, observamos que a subjetividade do corpo saudável se constrói orientada principalmente pelos imperativos de buscar sempre mais e melhor em termos de saúde do corpo e qualidade de vida. Tal orientação articula os comportamentos associados a essa subjetividade às prescrições enunciadas por instituições de saúde, especialmente aquelas de ordem médica, que exercem, assim, sua função corretivadisciplinar. Daí nosso entendimento de que o corpo saudável constitui macronarrativa simbolicamente estruturada na memória coletiva, a partir do exercício discursivo das instituições disciplinares, no intuito de produzir uma verdade hegemônica a respeito da saúde do corpo (DANTAS, 2007).

Enquanto construção subjetiva discursivamente moldada por injunções e por interesses sócio-históricos de ordens distintas, o corpo saudável se identifica com os sujeitos por meio de verdades biomédicas universalizantes. Uma face dessa universalização se apresenta pela incorporação social do pensamento técnico-instrumental da ciência moderna, por meio do qual se edificam e se consolidam os conhecimentos e as concepções de saúde da medicina ocidental. A esse domínio, Dantas (2007) nos lembra que o corpo, em seu envolvimento simbólico e como objeto concreto de investimentos coletivos, torna-se reflexo da vida social e que, com isso, práticas discursivas midiáticas passam a orientar a autoconstrução da realidade corporal dos sujeitos. É a partir desses apontamentos que refletimos o saudável como estandarte do corpo fisicamente ativo e capaz, cultuado e celebrado em termos de perfeição estética e moral e midiaticamente mediado.

Nesse sentido, o esporte midiático apresenta-se como um local privilegiado para observar os modos como a produção de discursos acerca da saúde do corpo se associam à celebração e à comodificação de símbolos de perfeição física, uma vez que, nesse local, a economia gira em torno de "mercadorias de identificação" (PARKER; WATSON, 2017). Tais mercadorias referem-se aos modos como aspectos da fisicalidade (em especial os constituintes de marcadores sociais, como classe, raça, sexo e nacionalidade) são mobilizados para a mediação e para a comodificação dos corpos em relação aos espectadores esportivos, diretos e indiretos. Exemplos dessa comodificação se fazem presentes de modo mais evidente nos trabalhos de Howe (2017) e Miller (2017), em que o corpo saudável é problematizado tanto como produto quanto como dispositivo de controle.

A comodificação dos corpos no contexto esportivo é focalizada nas discussões do pesquisador David Rowe (2017), que elucida mecanismos midiáticos e relações de poder- 
saber que atravessam tal ação no mercado do entretenimento, além de desvelar como a subjetividade do corpo saudável incita estilos de vida formulados em torno das perspectivas do corpo fisicamente ativo e capaz na esfera sociocultural, estimulando o consumo da perfeição física. Rowe (2017) explica que a mediação do corpo, referindo-se às representações simbólicas e midiáticas que o significa, estabelece processos hegemônicos interconectados que reconfiguram e reaproveitam o corpo constantemente, adequando-o, assim, às formas de geração de lucro existentes no contexto esportivo e para além dele, a exemplo da venda de implementos esportivos, adornos e afins.

Rowe (2017) pontua que o corpo mediado "não é apenas capturado e exibido de várias maneiras para o lucro, mas também modificado de maneiras que obscurecem os limites entre o físico e o imaterial" (ROWE, 2017, p. 238, tradução nossa), como é possível observar em seu trabalho em relação à produção do corpo célebre esportivo. Tal produção implica submetê-lo a uma rígida disciplina, a fim de adequá-lo aos distintos espaços do social, construindo, assim, imagens do corpo passíveis de comercialização, dentro e fora desse contexto. Essa adequação do corpo esportivo às demais esferas da vida social busca torná-lo acessível a qualquer indivíduo, e sua disciplinarização se dá no intuito de que as qualidades desse corpo possam ser transfiguradas às propriedades imaginárias dos espectadores e, assim, apropriadas por eles.

O esforço para produzir a identidade de um corpo célebre, comodificável aos moldes midiáticos, compreende a adequação de suas particularidades em um produto para venda de determinada subjetividade. Essa estratégia mercantil pode ser analisada como um esforço para informar a subjetividade do corpo saudável e disseminá-la socialmente, visto que o corpo esportivo mediado - predominantemente o da celebridade - constitui-se como sinônimo de saúde e qualidade de vida em nossa cultura. Assim, além de reforçar os valores presentes em uma dada relação de poder-saber hegemônica, a exemplo do que, em outra perspectiva teórica, Crawford (2006) chama de "ideologia da classe média", o corpo esportivo constitui instrumento de mediação de saberes que atuam na produção e na socialização da subjetividade do corpo saudável.

Diante desse cenário, atentamos para a produção mercantil do corpo saudável sobre uma utilização estratégica das compreensões de saúde e para seu envolvimento com a institucionalização de uma política de individualização da responsabilidade pela saúde, para além de outros aspectos da vida humana. Esses apontamentos amparam-se nas discussões propostas por Safai (2017), que argumenta sobre seus efeitos em relação à hiper-promoção da melhora da qualidade de vida individual ao invés da sustentação de uma crítica pública que 
questione as consequências negativas à saúde promovidas pelo êxodo industrial, postura que contribui para a ausência de debates e discussões públicas a respeito das interfaces social, política e econômica da saúde.

A autora atenta, também, para a exploração industrial e mercantil das formas de produção e administração social da doença e para a negligência da responsabilidade coletiva pelos cuidados de saúde. Para ela, o ocultamento dessas posturas é reflexo da promoção da individualização dos estilos de vida, exercida e regulada pelos regimes neoliberais. Nesse cenário, a busca pela perfeição da forma física e pela saúde do corpo toma a forma de imperativo de desempenho em interdependência com a noção de risco que coloca o corpo saudável como seu produto e/ou efeito (SAFAI, 2017; MOULIN, 2011). Assim operam as tecnologias de poder neoliberais sobre os corpos e sobre suas individualidades, regulando formas de pensar e se comportar em relação à saúde ou, em outros termos, subjetivando-os e institucionalizando certa compreensão de saúde.

\section{0 corpo saudável como dispositivo disciplinar}

O envolvimento tecnológico dos corpos dá vazão a uma nova forma de exercer sobre eles o poder disciplinar. Com a produção de uma verdade social medicalizada, em que a saúde constitui imperativo recorrente nos discursos institucionais, o corpo saudável torna-se um dispositivo de poder que estrutura os sentidos desses discursos na realidade. $O$ funcionamento desse dispositivo ocorre, como analisamos, pela inscrição desses sentidos - especialmente aqueles relacionados aos benefícios da saúde para a qualidade de vida e para a longevidade no imaginário coletivo. Tais sentidos são frequentemente articulados a uma pretensa necessidade de se sobressair e de obter bons desempenhos nas demais dimensões da vida humana, associado ao discurso neoliberal, bem como às punições da ordem do exercício (FOUCAULT, 2005).

As punições da ordem do exercício caracterizam-se por um aprendizado intensificado, multiplicado e repetido em relação às normas de conduta social. Por meio delas, espera-se passar pela "expiação" e pelo "arrependimento" como "efeito corretivo" do exercício mecânico do castigo, como resposta ao contato do sujeito com o poder disciplinar (FOUCAULT, 2005; 2014). Tais punições fazem parte do jogo da quantificação, descrito por Foucault (2014), em que há hierarquização dos "bons" e dos "maus" sujeitos, diferenciandoos em função de seus atos e de seus valores, de suas virtualidades, qualidades, competências e/ou aptidões. Ademais, essas punições recorrem, com frequência, às narrativas de 
incapacidade do sujeito gestadas pelas formas de naturalização da individualização da responsabilidade pela vida, em última instância (Cf. CRAWFORD, 2006; SAFAI, 2017).

Esses aspetos nos incitam à pergunta: qual a punição direcionada aos corpos nãoconformes com os ideais enunciados pelos discursos de saúde do corpo em nossa sociedade? Colocamos em perspectiva, por meio dessa questão, que a condição de não-saudável implica numa subjetividade que escapa à ordem à qual se voltam as normas prescritivas de comportamento instituídas pelos discursos médicos. Além disso, ressaltamos o reforço disciplinar e normativo que as demais instituições exercem para a operação de tais discursos e normas, uma vez que o funcionamento da rede do poder se dá no sentido de alimentar tal estrutura, fazendo funcionar, por exemplo, saberes que classificam tais corpos como "maus".

A exemplo desse funcionamento discursivo operado pelo dispositivo do corpo saudável temos o estudo desenvolvido por Gard (2017), em que analisa o que chama de cultura epistemológica da pesquisa sobre obesidade. Gard (2017) argumenta acerca da narrativa emergente na década de 1970, que considera o peso corporal uma ameaça à saúde humana e, portanto, uma condição médica séria. Em seu argumento, o autor ressalta a influência do meio científico na construção dessa narrativa, discutindo a baixa qualidade do pouco conhecimento útil ofertado por pesquisas sobre peso corporal fundamentadas no "mito fundador" do equilíbrio entre consumo e gasto calórico.

Apontando para o aumento da confusão acerca dos conhecimentos produzidos em torno do peso corporal e da epidemia da obesidade - confusão que o autor atribui às contradições dos resultados produzidos e disponibilizados - Gard (2017) discute, ainda, a postura dos periódicos acadêmicos em relação à publicação desses conhecimentos. Como ressalta, a relutância dos periódicos em aceitar a publicação de descobertas nulas corrobora com o exagero e/ou com a adulteração dos dados de pesquisa, postura que compromete o meio científico tanto quanto as intervenções em saúde. Além disso, contribui, de acordo com o autor, para o desenvolvimento do mercado da medicina alternativa e para a virada epistemológica do que "é verdadeiro" para "o que funciona”, da qual decorre o redirecionamento das formas de intervenção em saúde pública para os aspectos comportamentais dos sujeitos.

Diante desse cenário, as análises foucaultianas a respeito das transformações na teoria da lei penal contribuem para refletir como a fisicalidade é codificada e suas relações com o poder disciplinar operado nos corpos saudáveis e não-saudáveis. Foucault (2005) aponta que a lei penal define o que é nocivo à sociedade e que o crime (falta moral ou religiosa) representa qualquer tipo de dano, perturbação ou incômodo a ela. Com esse estabelecimento, o sujeito 
identificado como criminoso ou infrator passa a ser aquele que rompe com o pacto social estabelecido pelas leis e pelas normas vigentes e, com a função de punir à justa pena, a reparação de danos promovida pelo poder disciplinar exercido juridicamente suscita o enquadramento do infrator. Para tanto, o exercício do poder disciplinar deve produzir um saber que, ao mesmo tempo, caracterize e ordene os sujeitos em torno da norma.

Dessa necessidade de enquadramento decorre o ajuste da legislação penal ao sujeito, não mais à sociedade, focalizando aquilo que ele se encontra na iminência de fazer (desejos, prazeres, gostos, vontades, pensamento e comportamentos) como alvo do poder disciplinar. Diante dessa reformulação, passa a prevalecer nas relações sociais a noção de periculosidade, que diz respeito à virtude dos comportamentos. Propõe-se, assim, o controle e a reforma do psicológico e da moral dos sujeitos, ou, nos termos de Foucault (2005 p. 86), uma “ortopedia social". Desse acontecimento emerge o modelo da sociedade disciplinar, marcada por "uma gigantesca série de instituições que vão enquadrar os sujeitos ao longo de sua existência" (FOUCAULT, 2005, p. 86).

Ressaltamos que a função do aparelho punitivo é fazer com que o infrator reaja ao mecanismo disciplinar, visto que o importante para a disciplinarização dos corpos é que esse mecanismo opere a reforma das ações que se manifestam como comuns, ocultas ou desinteressantes da cotidianidade dos sujeitos. Assim, o poder disciplinar envolve a alteração e a automatização de hábitos e de comportamentos, bem como de práticas coletivas, por meio das punições, entendidas pelo autor como tudo aquilo que é capaz de fazer o sujeito sentir a falta cometida. A falta, por sua vez, designa a incapacidade do sujeito de atingir o nível ideal informado pelas normas, sendo expressa como delito e traduzida em termos de inaptidão para cumprir tarefas (FOUCAULT, 2005).

Por meio de suas funções repressora e punitiva, as disciplinas tornam penalizáveis as particularidades mais efêmeras da conduta individual (tempo, discursos, atividades, maneiras de ser, sexualidade e corpo). Ademais, Foucault (2014) aponta para o funcionamento de um mecanismo penal no interior de todos os sistemas disciplinares ao explicar que, por meio das disciplinas, o estabelecimento de uma 'infra-penalidade' funciona como um pequeno mecanismo penal exercido na ausência dos grandes sistemas disciplinares, encarregando-se dos espaços deixados vazios pelas leis, bem como da função de qualificar e reprimir os conjuntos de comportamento que lhes escapam. Daí a ressalva de que a especificidade do mecanismo de punição disciplinar se apresenta pela 'inobservância' das regras, enquadrando o não-conforme de acordo com normas sociais. 
Diante dessas constatações, inferimos que os corpos não-saudáveis que negam, em certa medida, os imperativos anteriormente discutidos, são enquadrados como ameaça ao corpo social pelo poder disciplinar. Tal enquadramento, como analisamos, caracteriza-os como infratores, visto que, quanto mais distantes das concepções de corpo saudável, mais esses corpos denunciam seu estilo de vida desconforme, desordenado. Essa denúncia, conferida a uma fisicalidade não-conforme confessa a ameaça desses corpos para discursos, imperativos e instituições de saúde instituídos na memória coletiva. É nesse nível que analisamos a codificação da fisicalidade em relação às operações do poder disciplinar nos corpos (não) identificados pela subjetividade do saudável, nos termos aqui apontados.

A codificação dos corpos, para Foucault (2014), pode ser definida em termos de codificação (marcar desvios e hierarquizar competências) e de disciplinarização (puni-los e recompensá-las). Esse duplo papel reflete o caráter ordinal de funcionamento da ordem penal disciplinar, sendo que "a disciplina, ao sancionar os atos com exatidão, avalia os indivíduos 'com verdade'; a penalidade que ela põe em execução se integra no ciclo de conhecimento dos indivíduos" (FOUCAULT, 2014, p. 151). Em função desse caráter são estabelecidos os estandartes mínimo, médio e ótimo aos quais os elementos comparativos da fisicalidade são aproximados, para que se meça e se hierarquize as capacidades 'naturais' dos sujeitos (FOUCAULT, 2014).

Desse modo, comportamentos, virtudes e particularidades próprios de cada sujeito acionam regras classificatórias de medição e de valoração que coagem os corpos à adequação e à conformidade. Por meio dessa coação, a fronteira do anormal é traçada, definindo o diferente em meio a todas as diferenças, exteriorizando-o como aquele a quem o olho do poder denuncia, a quem as práticas de exame qualificam e a quem as sansões normalizadoras disciplinam. Assim funciona o dispositivo do corpo saudável, garantindo e operando o exercício constante do poder disciplinar nos corpos, igualando os sujeitos por meio do mérito conferido à conformidade de seus comportamentos e, assim, distribuindo-os nos espaços sociais.

\section{Considerações finais}

Esse artigo se propôs a analisar o envolvimento discursivo do corpo saudável com manifestações do mecanismo disciplinar de instituições médicas de saúde. As discussões propostas atentam para aspectos afetos à subjetivação e à institucionalização dos corpos, à codificação discursiva da fisicalidade e à produção de uma subjetividade específica frente à 
rede desses mecanismos constituintes da cultural física. Ao focalizar essa rede e suas relações de poder-saber disciplinares, por meio de sua inscrição nos corpos e na memória coletiva, buscamos evidenciar seus efeitos discursivos, como a produção e o exercício frequente e constante de normas prescritivas que, ao incitarem a disciplinarização dos corpos em torno de mercadorias físicas de identificação, constituem subjetividade em torno da qual se estrutura toda uma tecnologia de normalização e de governamentalidade.

Em nossa realidade social atual, observamos os dispositivos de saúde exercendo força maior na governamentalidade dos corpos, reforçando suas operações disciplinares nas experiências in-corporadas (embodied) dos sujeitos, uma vez que acionam um número maior de imperativos orientados à transformação e à adaptação de/a formas específicas de socialização. O enfrentamento das formas de institucionalização dos corpos possibilita novas perspectivas reflexivas que conduzem a transformações nas formas como nos comportamos, bem como nos modos como interagimos com a realidade e com os significados dele emergentes. Um exemplo disso pode ser observado no estudo de Amorim et al. (2017), em que investiga desafios e possiblidades para intervenções com práticas corporais na perspectiva da desinstitucionalização em um hospital psiquiátrico brasileiro.

Amorim et al. (2017, p. 40) destacam que "o modo como se entende o corpo afetará diretamente as relações de poder-saber na instituição", assim como os modos como se entende a saúde afetam tais relações. Nesse sentido, o corpo pode ser enfrentado como objeto acometido por uma doença e, assim, objeto de exame e dependência institucional ou, ainda, como espaço de subjetividade e comunicação afetiva com as formas de produção culturais. Os autores nos possibilitam observar que o modo como entendemos o corpo e como enfrentamos as questões de saúde transforma as práticas sociais, especialmente consideradas em relação à existência e ao sofrimento dos sujeitos frente aos processos de humanização.

Diante desse cenário, ressaltamos a necessidade de buscarmos formas autorreflexivas crítica e politicamente engajadas que instiguem a pensar ativamente os modos como produzimos conhecimentos e construímos os saberes que orientam as relações sociais, a que se propõe o campo dos estudos culturais físicos. Nesse sentido, vale lembrar a recomendação de Howe (2017) de que a agenda dos estudos culturais físicos priorize metodologias de observação participante e in-corporadas (embodied), mediando-se pela fisicalidade e, assim, abraçando métodos sensuais e diversidades teóricas para a promoção do exercício praxiológico de modo mais radical.

Baseiam-se nessa recomendação os esforços empreendidos na construção desse artigo, que propõe reflexões acerca das formas como a fisicalidade é socialmente codificada em suas 
relações com o poder disciplinar, especificamente quanto aos corpos (não) saudáveis. Tais esforços materializam compromissos e preocupações em informar os posicionamentos e os espaços ocupados pelos corpos em meio à rede cultural física, articulados à reflexividade em relação aos saberes institucionalizados e operados na ordem medicalizante e disciplinar dos sujeitos e de suas relações afetivas.

\section{Referências}

AMORIM, A. K. M. A. et al. Práticas corporais e desinstitucionalização em saúde mental: desafios e possibilidades. Estudos de Psicologia, v. 22, n. 1, p. 39-49, jan./mar. 2017. Disponível em: http://pepsic.bvsalud.org/scielo.php?script=sci_arttext\&pid=S1413294X2017000100005. Acesso em: 22 mai. 2020.

BATISTELLA, C. E. C. Abordagens contemporâneas do conceito de saúde. In: O Território e o Processo Saúde-Doença. Rio de Janeiro: Arca Fiocruz, 2007. p. 51-86.

CHAUÍ, M. O que é ideologia. São Paulo: Brasiliense, 2008. 119 p.

CORBIN, A.; COURTINE, J. J.; VIGARELLO, G. (Orgs.). História do corpo: as mutações do olhar no século XX. Petrópolis: Vozes, 2011, 1792 p.

CRAWFORD, R. Health as a meaningful social practice. Health, v. 10, n. 4, p. 401-420, mai. 2006. Disponível em: https://journals.sagepub.com/doi/10.1177/1363459306067310. Acesso em: 21 mai. 2020.

CSORDAS, T. J. Embodiment and experience: the existential ground of culture and self. Cambridge: Cambridge University Press, 1994.

DANTAS, E. R. A produção biopolítica do corpo saudável: mídia e subjetividade na cultura do excesso e da moderação. 2007. 211 F. Tese (Doutorado em Educação) - Centro de Ciências Sociais Aplicadas, Universidade Federal do Rio Grande do Norte, Natal. 2007.

FOUCAULT, M. A verdade e as formas jurídicas. Rio de Janeiro: NAU, 2005. 159 p.

FOUCAULT, M. A ordem do discurso. Aula inaugural no Collège de France, pronunciada em 2 de dezembro de 1970. 13 ed. São Paulo: Edições Loyola, 2006a.

FOUCAULT, M. "Poder e saber/ Poderes e estratégias/ Diálogo sobre o poder". Ditos \& Escritos IV. Rio de Janeiro: Forense Universitária, 2006b, p. 223-266.

FOUCAULT, M. Nascimento da biopolítica: curso dado no Collège de France (1878-1979). Eduardo Brandão. São Paulo: Martins Fontes, 2008.

FOUCAULT, M. Microfísica do poder. São Paulo: Graal, 2012. 
FOUCAULT, M. Vigiar e punir: nascimento da prisão. Petrópolis: Vozes. 2014.

FOUCAULT, M. História da sexualidade: a vontade de saber. São Paulo: Paz \& Terra, 2015.

FRANCOMBE-WEBB, J.; RICH, E.; DEPIAN, L. I move like you... but different: biopolitics and embodied methodologies. Cultural Studies - Critical Methodologies, v. 14, n. 5, p. 471-482, 2014.

FRANCOMBE-WEBB, J.; SILK, M. Young girls' embodied experiences of femininity and social class. Sociology, v. 50, n. 6, p. 652-672, 2016.

FULLAGAR, S. A physical cultural studies perspective on physical (in) activity and health inequalities: the biopolitics of body practices and embodied movement. Tempos e Espaços em Educação., v. 12, n. 28, p. 63-76, jan. 2019. DOI: 10.20952. Disponível em: https://seer.ufs.br/index.php/revtee/article/view/10161. Acesso em: 21 mai. 2020.

GARD, M. Fat bodies. In: SILK, M.; ANDREWS D.; THORPE, H. (Orgs.). Routledge Handbook of Physical Cultural Studies. London and New York: Routledge International Handbooks, 2017. p. 228-236.

GIARDINA, M.; NEWMAN, J. What is this 'physical' in physical cultural studies? Sociology of Sport Journal, v. 28, n. 1, p. 36-63, 2011. DOI: 10.1123/ssj.28.1.36. Disponível em: https://journals.humankinetics.com/view/journals/ssj/28/1/articlep36.xml?tab body=contributorNotes-6615. Acesso em: 21 mai. 2020.

HOWE, D. (Dis)abled bodies. In: SILK, M.; ANDREWS D.; THORPE, H. (Orgs.). Routledge Handbook of Physical Cultural Studies. London and New York: Routledge International Handbooks, 2017. p. 159-166.

LARA, L. M. Corpo, sentido ético-estético e cultura popular. Maringá: Eduem, 2011. 247 p.

LARA, L. M.; RICH, E. Os estudos de cultura física na Universidade de Bath - Reino Unido: dimensões de uma abordagem muito além da fisicalidade. Movimento, v. 23, n. 4, p. 13111324, out. 2017. Disponível em https://seer.ufrgs.br/Movimento/article/view/74326. Acesso em: 21 mai. 2020.

LARA, L. M. Pesquisa e ensino em corpo, cultura e ludicidade em tempos de adversidades. In: LARA, L. M.; LOPES, B.R.; SOUZA, V.F.M. (Orgs.). Simpósio estudos culturais na educação física: 15 anos de pesquisa em corpo, cultura e ludicidade, 1., 2019, Maringá. Anais [...]. Maringá: GPCCL, 2019.

LARA, L. M.; LOPES, B.R.; SOUZA, V.F.M. (Orgs.). Simpósio estudos culturais na educação física: 15 anos de pesquisa em corpo, cultura e ludicidade, 1., 2019, Maringá. Anais [...]. Maringá: GPCCL, 2019.

MARQUES, J. P. Experiências do corpo nos estudos culturais e saberes formativos na educação física: subjetivação, institucionalização, saúde e disciplina. In: LARA, L. M.; LOPES, B.R.; SOUZA, V.F.M. (Orgs.). Simpósio estudos culturais na educação física: 15 anos de pesquisa em corpo, cultura e ludicidade, 1., 2019, Maringá. Anais [...] Maringá: GPCCL, 2019b. 
MARQUES, J. P.; MIRANDA, A. C. M.; LARA, L. M. Corpos subjetivados e institucionalizados: um estudo da cultura física na obra Routledge Handbook of Physical Cultural Studies. In: $28^{\circ}$ Encontro Anual de Iniciação Científica, 2019, Maringá. Anais [....] Maringá, 2019.

MILLER, T. Spectacular and eroticized bodies. In: SILK, M.; ANDREWS D.; THORPE, H. (Orgs.). Routledge Handbook of Physical Cultural Studies. London and New York: Routledge International Handbooks, 2017. p. 257-264.

MINISTÉRIO DA SAÚDE. Saúde e Direitos Humanos. Rio de Janeiro: Fundação Oswaldo Cruz, Grupo Direitos Humanos e Saúde Helena Besserman, 2011.

MOULIN, A. M. O corpo diante da medicina. In: CORBIN, A.; COURTINE, J.J.; VIGARELLO, G. (Orgs.). História do corpo: as mutações do olhar no século XX. Petrópolis: Vozes, 2011. p. 16-62.

PARKER, A.; WATSON, N. Spiritualized and religious bodies. In: SILK, M.; ANDREWS D.; THORPE, H. (Orgs.). Routledge Handbook of Physical Cultural Studies. London and New York: Routledge International Handbooks, 2017. p. 209-217.

PRADO, J. L. A. As narrativas do corpo saudável na era da Grande Saúde. Contemporânea, v. 5, n. 1, p. 1-26, dez. 2007, DOI: 10.9771/1809-9386. Disponível em: https://portalseer.ufba.br/index.php/contemporaneaposcom/article/view/3505. Acesso em: 21 mai. 2020.

ROWE, D. Mediated bodies and commodified bodies. In: SILK, M.; ANDREWS D.; THORPE, H. (Orgs.). Routledge Handbook of Physical Cultural Studies. London and New York: Routledge International Handbooks, 2017. p. 237-245.

SAFAI, P. Medicalized and scientized bodies. In: SILK, M.; ANDREWS D.; THORPE, H. (Orgs.). Routledge Handbook of Physical Cultural Studies. London and New York: Routledge International Handbooks, 2017. p. 191-199.

SANTOS, M. A. et al. Corpo, saúde e sociedade de consumo: a construção social do corpo saudável. Saúde e Sociedade, v. 28, p. 239-252, 2019. Disponível em: https://www.scielosp.org/article/sausoc/2019.v28n3/239-252/. Acesso em: 30 jun. 2020.

SILK, M.; ANDREWS, D.; THORPE, H. (Orgs.). Routledge Handbook of Physical Cultural Studies. London and New York: Routledge International Handbooks, 2017. 610 p.

VIEIRA, A. P. Dança, educação e contemporaneidade: dilemas e desafios sobre o que ensinar e o que aprender. In: LARA, L. M. (Org.). Dança: dilemas e desafios na contemporaneidade. Maringá: Eduem, 2013. p. 155-184. 